\title{
Real-time effects of PEEP and tidal volume on regional ventilation and perfusion in experimental lung injury
}

João Batista Borges ${ }^{1 *}$ (D), John N. Cronin ${ }^{1}$, Douglas C. Crockett ${ }^{2}$, Göran Hedenstierna ${ }^{3}$, Anders Larsson ${ }^{4}$ and Federico Formenti ${ }^{1,2^{*}}$

\section{* Correspondence:}

joaobatistaborges8@gmail.com; federico.formenti@kcl.ac.uk ${ }^{1}$ Centre for Human and Applied Physiological Sciences, King's College London, London, UK Full list of author information is available at the end of the article

\begin{abstract}
Background: Real-time bedside information on regional ventilation and perfusion during mechanical ventilation (MV) may help to elucidate the physiological and pathophysiological effects of MV settings in healthy and injured lungs. We aimed to study the effects of positive end-expiratory pressure (PEEP) and tidal volume $\left(V_{T}\right)$ on the distributions of regional ventilation and perfusion by electrical impedance tomography (EIT) in healthy and injured lungs.
\end{abstract}

Methods: One-hit acute lung injury model was established in 6 piglets by repeated lung lavages (injured group). Four ventilated piglets served as the control group. A randomized sequence of any possible combination of three $V_{T}(7,10$, and $15 \mathrm{ml} / \mathrm{kg}$ ) and four levels of $\operatorname{PEEP}\left(5,8,10\right.$, and $\left.12 \mathrm{cmH}_{2} \mathrm{O}\right)$ was performed in all animals. Ventilation and perfusion distributions were computed by EIT within three regionsof-interest (ROIs): nondependent, middle, dependent. A mixed design with one between-subjects factor (group: intervention or control), and two within-subjects factors (PEEP and $V_{T}$ ) was used, with a three-way mixed analysis of variance (ANOVA).

Results: Two-way interactions between PEEP and group, and $V_{T}$ and group, were observed for the dependent $\mathrm{ROI}(p=0.035$ and 0.012 , respectively), indicating that the increase in the dependent $\mathrm{ROI}$ ventilation was greater at higher PEEP and $\mathrm{V}_{T}$ in the injured group than in the control group. A two-way interaction between PEEP and $V_{T}$ was observed for perfusion distribution in each ROI: nondependent ( $p=$ $0.030)$, middle $(p=0.006)$, and dependent $(p=0.001)$; no interaction was observed between injured and control groups.

Conclusions: Large PEEP and $V_{T}$ levels were associated with greater pulmonary ventilation of the dependent lung region in experimental lung injury, whereas they affected pulmonary perfusion of all lung regions both in the control and in the experimental lung injury groups.

Keywords: Respiratory distress syndrome, Adult, Mechanical ventilation, Electrical impedance tomography, Pulmonary circulation, Ventilation-perfusion ratio

\section{Introduction}

Real-time information on regional ventilation and perfusion, and their changes, during mechanical ventilation (MV) may help elucidate the physiological and pathophysiological effects of MV settings in healthy and injured lungs.

(c) The Author(s). 2020 Open Access This article is distributed under the terms of the Creative Commons Attribution 4.0 International License (http://creativecommons.org/licenses/by/4.0/), which permits unrestricted use, distribution, and reproduction in any medium, provided you give appropriate credit to the original author(s) and the source, provide a link to the Creative Commons license, and indicate if changes were made. 
A single-compartment model of the healthy lung can describe aeration and its changes associated with a homogeneous distribution of airway pressures, expansion, and stretching across the lung parenchyma [1]. The positive airway pressure applied during MV may affect pulmonary ventilation and perfusion distributions, and their tidal changes, especially in the presence of acute lung injury.

The effects of positive end-expiratory pressure (PEEP) on the regional distribution of tidal volume $\left(V_{\mathrm{T}}\right)$ and recruitment have been investigated by chest computed tomography in sedated-paralyzed patients with the acute respiratory distress syndrome (ARDS) [2]. It was evidenced that PEEP made the gas distribution more homogeneous, stretching the upper levels and recruiting the lower ones [2].

Electrical impedance tomography (EIT) has emerged as a new functional-imaging method potentially meeting many clinical needs. It is a non-invasive, radiation-free tool to monitor, in real-time and at the bedside, the distribution of pulmonary ventilation [3-11]. Subjecting the patient's chest to minute electrical currents, EIT measures the electric potentials at the chest wall surface to produce two-dimensional (2D) images that reflect the impedance distribution within the thorax. Cyclic variations in pulmonary air and blood content are the major determinants for the changes in thoracic impedance. Because cyclic changes in local impedance mainly correspond to changes in lung aeration, EIT can reliably assess imbalances in the distribution of regional ventilation $[3,4,11,12]$. Besides other features like portability and the possibility of aroundthe-clock monitoring, the high temporal resolution (modern EIT devices generate up to 50 images per second) is another important aspect of this imaging method, which also allows the study of rapid physiological phenomena, such as the regional perfusion [13].

We aimed to measure pulmonary regional ventilation and perfusion at 12 combinations of PEEP and $V_{\mathrm{T}}$ levels in piglets with saline lavage-induced lung injury and in mechanically ventilated control piglets. We sought to determine (1) if the PEEP and $V_{\mathrm{T}}$ effects on the regional distribution of tidal volume in injured lungs are also detectable by EIT; (2) whether there are also effects on perfusion; and (3) does the presence or absence of injury affect PEEP- or $V_{\mathrm{T}}$-related changes in ventilation and perfusion distributions.

\section{Materials and methods}

The study was performed at the Hedenstierna Laboratory, Uppsala University. The Regional Animal Ethics Committee approved the study.

Eleven piglets (2-3 months old, weight $30.7 \pm 1.5 \mathrm{~kg}$, mean $\pm \mathrm{SD}$ ) of mixed Hampshire, Yorkshire, and Swedish country breeds were included in the study. All animals were studied lying in the supine position under general anesthesia with mandatorymode mechanical ventilation provided via tracheostomy. They were pre-medicated with intramuscular xylazine $2 \mathrm{mg} / \mathrm{kg}$, ketamine $20 \mathrm{mg} / \mathrm{kg}$, and midazolam $0.5 \mathrm{mg} / \mathrm{kg}$. An ear vein was cannulated and intravenous ketamine $32 \mathrm{mg} / \mathrm{kg} / \mathrm{h}$, fentanyl $4 \mathrm{mcg} / \mathrm{kg} / \mathrm{h}$, and midazolam $0.16 \mathrm{mg} / \mathrm{kg} / \mathrm{h}$ were administered. Adequacy of anesthesia was confirmed by the absence of reaction to painful stimulation between the front hooves and the absence of any signs of sympathetic stimulation after paralysis. Muscle relaxation was achieved using continuous infusion of rocuronium titrated against the spontaneous respiratory effort. Normovolemia was maintained with intravenous infusion of Ringer's lactate solution at $20 \mathrm{ml} / \mathrm{kg} / \mathrm{h}$ for the first hour followed by $10 \mathrm{ml} / \mathrm{kg} / \mathrm{h}$. 
MV was performed using a Servo-I ventilator (Maquet, Rastatt, Germany). During the instrumentation phase, ventilation was provided in volume-controlled mode, with $V_{\mathrm{T}}$ of $10 \mathrm{ml} / \mathrm{kg}$, respiratory rate (RR) 25 breaths/min, PEEP $5 \mathrm{~cm} \mathrm{H} \mathrm{H}_{2} \mathrm{O}$, inspiratory-toexpiratory (I:E) ratio 1:2, and fraction of inspired oxygen $\left(\mathrm{F}_{\mathrm{I}} \mathrm{O}_{2}\right)$ 0.4. ECG, invasive systemic, central venous, and pulmonary artery blood pressures were transduced using a standard clinical monitor (IntelliVue M8004A, Philips Healthcare, Best, Netherlands). Digital outputs from the ventilator and clinical monitor were continuously recorded using the acqIS software (EPiQ Life Science AB, Kista, Sweden). A femoral artery was cannulated for pulse contour cardiac output monitoring (PiCCO, Pulsion Medical Systems, Munich, Germany). Pulmonary artery flotation catheter thermodilution cardiac output measurements and arterial blood gas analyses were performed at the beginning and end of the scanning series for each animal.

\section{Acute lung injury model}

Following baseline measurements, a one-hit acute lung injury model was established in 7 randomly chosen animals (injured group), with repeated lung lavages $(30 \mathrm{ml} / \mathrm{kg})$ of isotonic saline applied until an arterial partial pressure of $\mathrm{O}_{2}$ and fraction of inspired oxygen ratio $\left(\mathrm{PaO}_{2} / \mathrm{F}_{\mathrm{I}} \mathrm{O}_{2}\right)$ of $200 \mathrm{mmHg}$ was reached. During the lavages, mechanical ventilation was set in pressure-controlled mode, with $\mathrm{F}_{\mathrm{I}} \mathrm{O}_{2}$ 1.0, RR 30, PEEP 5, and a driving pressure resulting in a $V_{\mathrm{T}}$ of $6 \mathrm{ml} / \mathrm{kg}$. If required, an infusion of noradrenaline (0.01 to $0.1 \mathrm{mcg} / \mathrm{kg} / \mathrm{min}$ ) was commenced following an injury to maintain adequate mean arterial blood pressure.

\section{Investigational protocol}

We studied the effects of combinations of PEEP and $V_{\mathrm{T}}$ on regional ventilation and perfusion by EIT in volume-controlled mode. A randomized sequence of any possible combination of three $V_{\mathrm{T}}(7,10$, and $15 \mathrm{ml} / \mathrm{kg})$ and four levels of PEEP $(5,8,10$, and 12 $\mathrm{cmH}_{2} \mathrm{O}$ ) was performed. In total, 12 conditions were studied.

\section{Electrical impedance tomography}

Pulmonary EIT data were recorded at $50 \mathrm{~Hz}$ with 32 electrodes equidistantly placed around the circumference of the thorax just below the level of the axilla (Enlight, TIMPEL SA, São Paulo, Brazil) $[13,14]$. The following functional images were generated by EIT:

1. Ventilation maps derived from relative impedance changes, which reliably track local, pixel-by-pixel changes in the content of air within the lung $[12,15]$. It is expressed as the percentage of total pulmonary ventilation through each of the three ROIs (total 100\%).

2. Perfusion maps obtained by injecting a bolus of $10 \mathrm{ml}$ of a hypertonic solution $(\mathrm{NaCl} 10 \%)$ into a central venous catheter during an expiratory breath hold for 20 s. Due to its high conductivity, $\mathrm{NaCl} 10 \%$ acts as an EIT contrast agent [16], which after injection into the right atrium during apnea passes through the pulmonary circulation, thereby producing a dilution curve that follows typical first-pass kinetics. The resulting regional impedance curves are then analyzed to quantitatively 
assess regional perfusion $[13,17,18]$, expressed as the percentage of total pulmonary blood flow through each of the three ROIs (total 100\%).

For the quantitative analysis of the ventilation and perfusion distributions by EIT, the lungs were sub-segmented into three isogravitational regions-of-interest (ROIs): nondependent, middle, and dependent regions (Fig. 1).

\section{Control group}

The same EIT imaging protocol and data analysis were performed in four animals, which did not receive saline lavages.

\section{Statistics}

The Shapiro-Wilk test was used to test data for normality. A mixed design with one between-subjects factor (group: intervention or control), and two within-subjects factors (PEEP and $V_{\mathrm{T}}$ ) was used, with a three-way mixed analysis of variance (ANOVA). The Bonferroni adjustment for multiple tests was applied for post hoc comparisons. The statistical analyses were conducted with SPSS (version 20; IBM Corp, IBM SPSS Statistics for Windows, Armonk, NY). Individual $p$ values to indicate statistical tests' significance are reported were relevant. Values presented are mean and SEM unless otherwise stated.

\section{Results}

The fatality rate was $1 / 11$ piglets, due to a cardiovascular event (this was in the injured group, thus 4 controls and 6 injured completed the study). The 10 piglets that survived the whole experiment were included in the analysis.

Just before starting the application of the twelve combinations of PEEP and $V_{\mathrm{T}}$, cardiopulmonary parameters were measured (Table 1). During the measurements of these cardiopulmonary parameters, mechanical ventilation was set in volume-controlled mode, with $\mathrm{F}_{\mathrm{I}} \mathrm{O}_{2} \quad 0.3-0.4$ for the control animals and $0.7-0.8$ for those with lung injury, RR 25, PEEP 5, and a $V_{\mathrm{T}}$ of $10 \mathrm{ml} / \mathrm{kg}$.

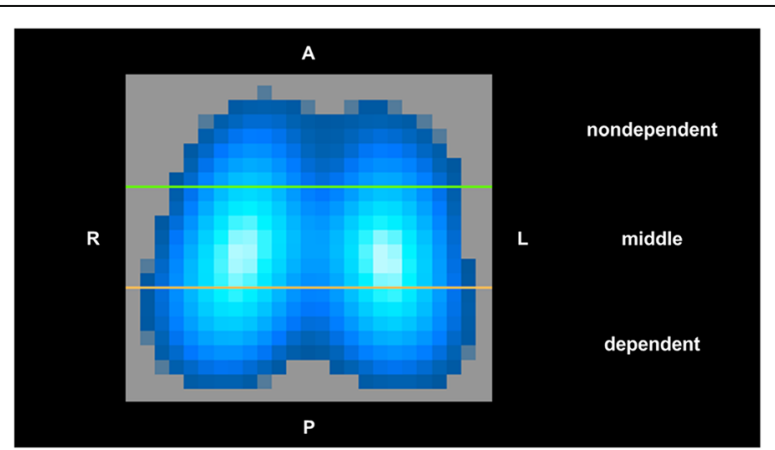

Fig. 1 Representative image of regional distribution of pulmonary ventilation as recorded by electrical impedance tomography (EIT) in one piglet from the control group. Three regions-of-interest (ROIs) of the same vertical height were constructed from top (anterior) to bottom (posterior) of the lung: nondependent, middle, and dependent ROI. In this ventilation map, lighter blue indicates greater ventilation than darker blue, with white representing the greatest ventilation. $A=$ anterior; $P=$ posterior; $L=l e f t ; R=$ right 
Table 1 Cardiopulmonary parameters

\begin{tabular}{|c|c|c|c|c|c|c|c|c|c|c|c|c|}
\hline \multirow[t]{2}{*}{ Parameter } & \multicolumn{4}{|c|}{ Control } & \multicolumn{6}{|c|}{ Injured } & \multirow{2}{*}{$\begin{array}{l}\text { Control } \\
\text { Mean (SD) }\end{array}$} & \multirow{2}{*}{$\begin{array}{l}\text { Injured } \\
\text { Mean (SD) }\end{array}$} \\
\hline & $\mathrm{C} 1$ & C2 & C3 & C4 & 11 & 12 & 13 & 14 & 15 & 16 & & \\
\hline Weight (kg) & 30 & 33 & 30 & 33 & 30 & 28 & 29 & 33 & 31 & 31 & $31(2)$ & $30(2)$ \\
\hline Lavage volume (L) & 0 & 0 & 0 & 0 & 4 & 5 & 2 & 4 & 9 & 2 & $0(0)$ & $4(3)$ \\
\hline $\mathrm{P} / \mathrm{F}$ ratio $(\mathrm{mmHg})$ & 287 & 384 & 441 & 373 & 158 & 206 & 153 & 104 & 164 & 143 & 371 (64) & $154(33)^{*}$ \\
\hline $\mathrm{ABP}(\mathrm{mmHg})$ & 65 & 78 & 89 & 79 & 68 & 95 & 97 & 97 & 75 & 62 & $78(10)$ & $82(16)$ \\
\hline PAP (mmHg) & 20 & 27 & 14 & 20 & 34 & 27 & 27 & 20 & 32 & 34 & $20(5)$ & $29(6) \#$ \\
\hline CVP (mmHg) & 6 & 11 & 11 & 6 & 13 & 8 & 11 & 6 & 8 & 12 & $9(3)$ & $10(3)$ \\
\hline HR (bpm) & 75 & 87 & 82 & 143 & 97 & 105 & 98 & 107 & 107 & 93 & $97(31)$ & $101(6)$ \\
\hline $\mathrm{CO}(\mathrm{L} / \mathrm{min})$ & 1.9 & 4.0 & 3.0 & 6.1 & 3.6 & 3.9 & 3.2 & 4.0 & 4.1 & 3.4 & $3.8(1.8)$ & $3.7(0.4)$ \\
\hline
\end{tabular}

Abbreviations: $C$ Control, I Injured ( $C 1$ to $C 4$ and $I 1$ to 16 refer to different animals), $P / F$ ratio $\mathrm{PaO}_{2} / \mathrm{F}_{1} \mathrm{O}_{2}$ ratio sampled at PEEP $5 \mathrm{cmH}_{2} \mathrm{O}, A B P$ mean arterial blood pressure, PAP Pulmonary arterial pressure, CVP Central venous pressure, $H R$ Heart rate, $\mathrm{CO}$ Cardiac output measured by pulmonary artery flotation catheter thermodilution ${ }^{*} p<0.001$

$" p=0.02$ from independent samples $t$ test

Data are presented as mean (SD), where appropriate

Figure 2 shows arterial partial pressure of $\mathrm{O}_{2}$ and fraction of inspired oxygen ratio (2A), mean airway pressure (2B), and cardiac output (2C) in the control (left) and injured (right) groups, in the 12 combinations of PEEP and $V_{\mathrm{T}}$.

Figure 3 shows representative EIT functional images illustrating the differences in the distribution of pulmonary ventilation and perfusion at two levels of PEEP and $V_{\mathrm{T}}$.

\section{Regional ventilation}

Figure 4 shows the distribution of regional pulmonary ventilation at different PEEP and $V_{\mathrm{T}}$ levels. Higher PEEP and $V_{\mathrm{T}}$ levels were associated with greater percent ventilation in the dependent ROI in the injured group than in the control group.

A two-way interaction between PEEP and group (injured/control) was observed for the dependent ROI $(p=0.035)$, with PEEP-related increase in dependent ROI ventilation being greater in the injured than in the control group.

A two-way interaction between $V_{\mathrm{T}}$ and group (injured/control) was also observed for the dependent ROI $(p=0.012)$, indicating that the increase in the dependent ROI ventilation was greater at higher $V_{\mathrm{T}}$ in the injured group than in the control group.

For instance, at PEEP $12 \mathrm{cmH}_{2} \mathrm{O}$ with $V_{\mathrm{T}} 15 \mathrm{ml} / \mathrm{kg}$ the dependent ROI ventilation in the injured group was $34.5 \pm 5.6 \%$ versus $22.0 \pm 2.4 \%$ at PEEP $5 \mathrm{cmH}_{2} \mathrm{O}$ with $\mathrm{V}_{\mathrm{T}} 7 \mathrm{ml} / \mathrm{kg}$.

\section{Regional perfusion}

No interactions between PEEP and group (injured/control) and/or between $V_{\mathrm{T}}$ and group (injured/control) were observed for regional perfusion.

Figure 5 shows the distribution of regional pulmonary perfusion at different PEEP and $V_{\mathrm{T}}$ levels. A two-way interaction between PEEP and $V_{\mathrm{T}}$ was observed for each ROI: nondependent $(p=0.030)$, middle $(p=0.006)$, and dependent $(p=0.001)$.

For instance, pooling together the two groups, at PEEP $5 \mathrm{cmH}_{2} \mathrm{O}$ with $V_{\mathrm{T}} 7 \mathrm{ml} / \mathrm{kg}$ versus PEEP $12 \mathrm{cmH}_{2} \mathrm{O}$ with $V_{\mathrm{T}} 15 \mathrm{ml} / \mathrm{kg}$ the nondependent ROI perfusion was $12.6 \pm$ $4.6 \%$ versus $10.2 \pm 3.7 \%$, the middle ROI perfusion was $54.3 \pm 5.9 \%$ versus $49.5 \pm 7.2 \%$, and the dependent ROI perfusion was $33.2 \pm 9.6 \%$ versus $40.2 \pm 9.7 \%$. 


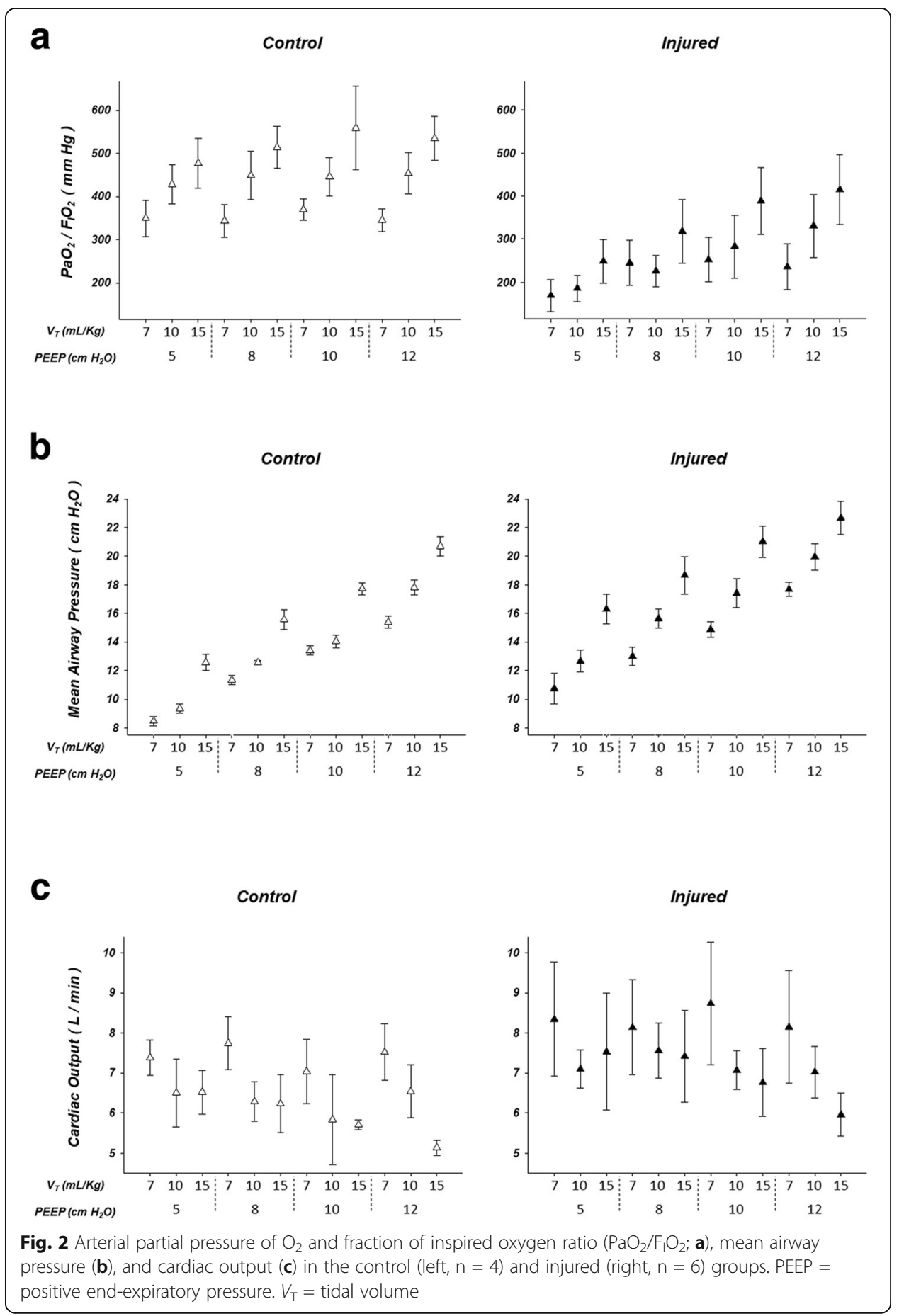

\section{Discussion}

Regional ventilation of the most dependent lung region was greater with larger PEEP and tidal volume in piglets with saline lavage-induced lung injury. In contrast, pulmonary blood flow of all lung regions was altered by larger PEEP and tidal volume both in control piglets and in piglets with saline lavage-induced lung injury.

Our study demonstrates that EIT can measure physiological and supra-physiological levels of pulmonary ventilation and perfusion, and their changes associated with different MV 


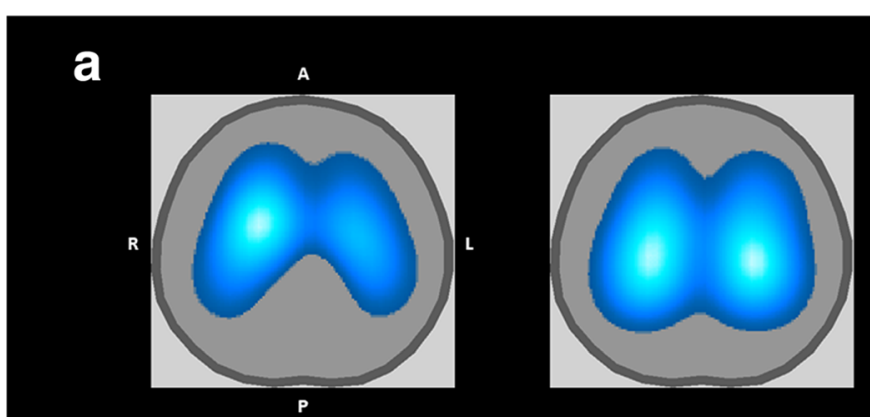

\section{b}

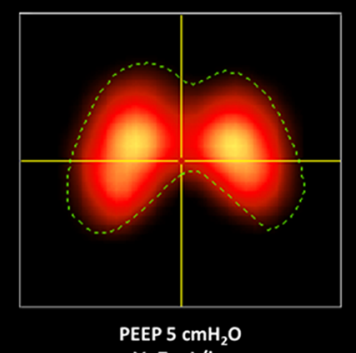

$\mathrm{V}_{\mathrm{T}} \mathrm{7 \textrm {mL }} / \mathrm{kg}$

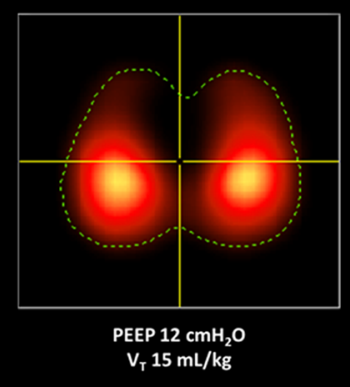

Fig. 3 Representative images of regional distribution of pulmonary ventilation (a) and perfusion (b) at two different PEEP and $V_{T}$ levels as recorded by electrical impedance tomography (EIT) in one piglet from the injured group. In the ventilation maps (a), lighter blue indicates greater ventilation than darker blue, with white representing the greatest ventilation. Similarly, in the perfusion maps (b), the lighter red indicates greater perfusion than darker red, with yellow indicating the greatest perfusion. The dotted line in the perfusion maps shows the contour of the corresponding ventilation map (i. e., the corresponding pulmonary ventilation area studied at the same point in time, hence under the same mechanical ventilation settings). $\mathrm{PEEP}=$ positive end-expiratory pressure. $V_{T}=$ tidal volume. $\mathrm{A}=$ anterior; $\mathrm{P}=$ posterior; $\mathrm{L}=$ left; $\mathrm{R}=$ right (all images)

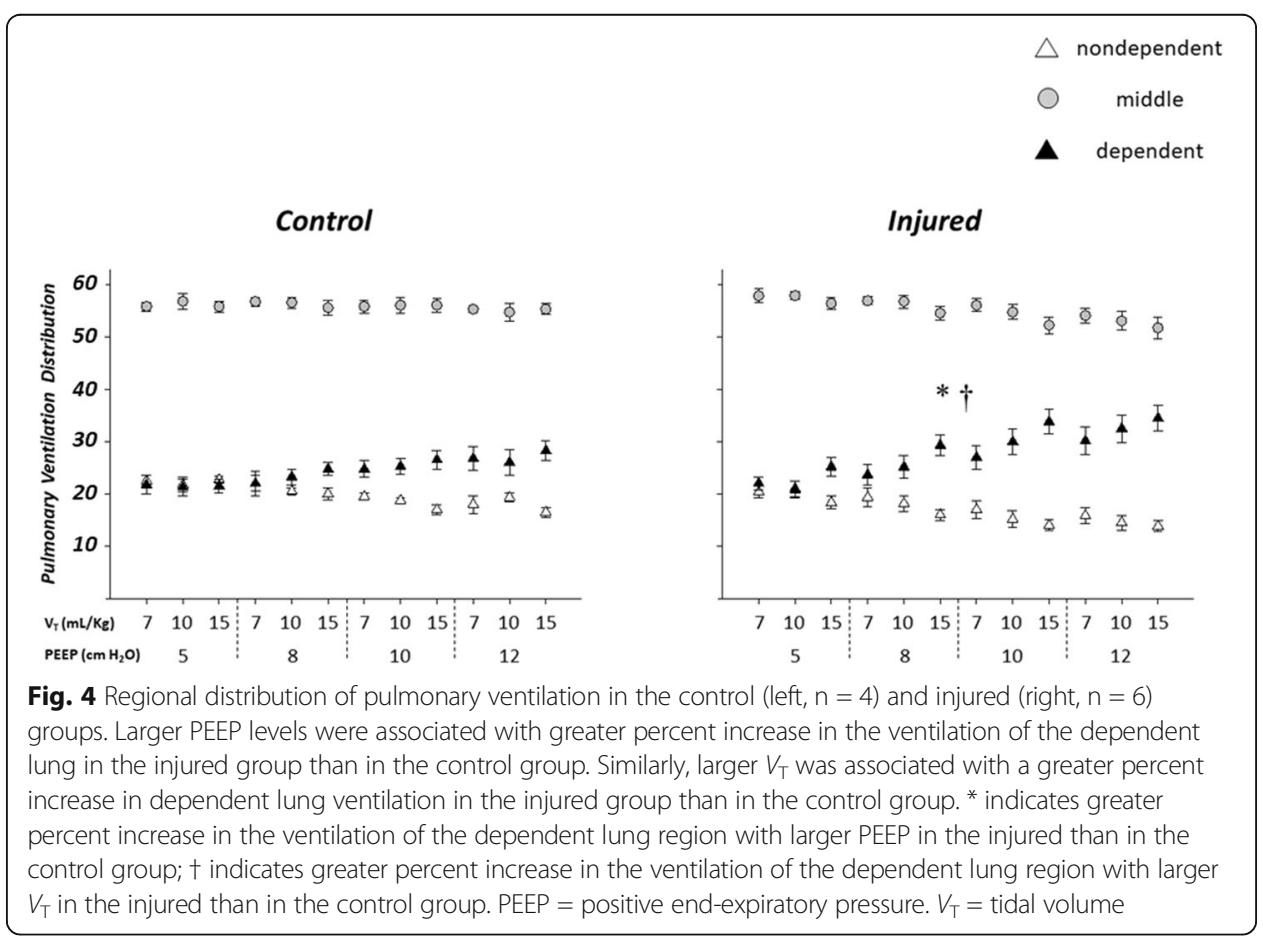




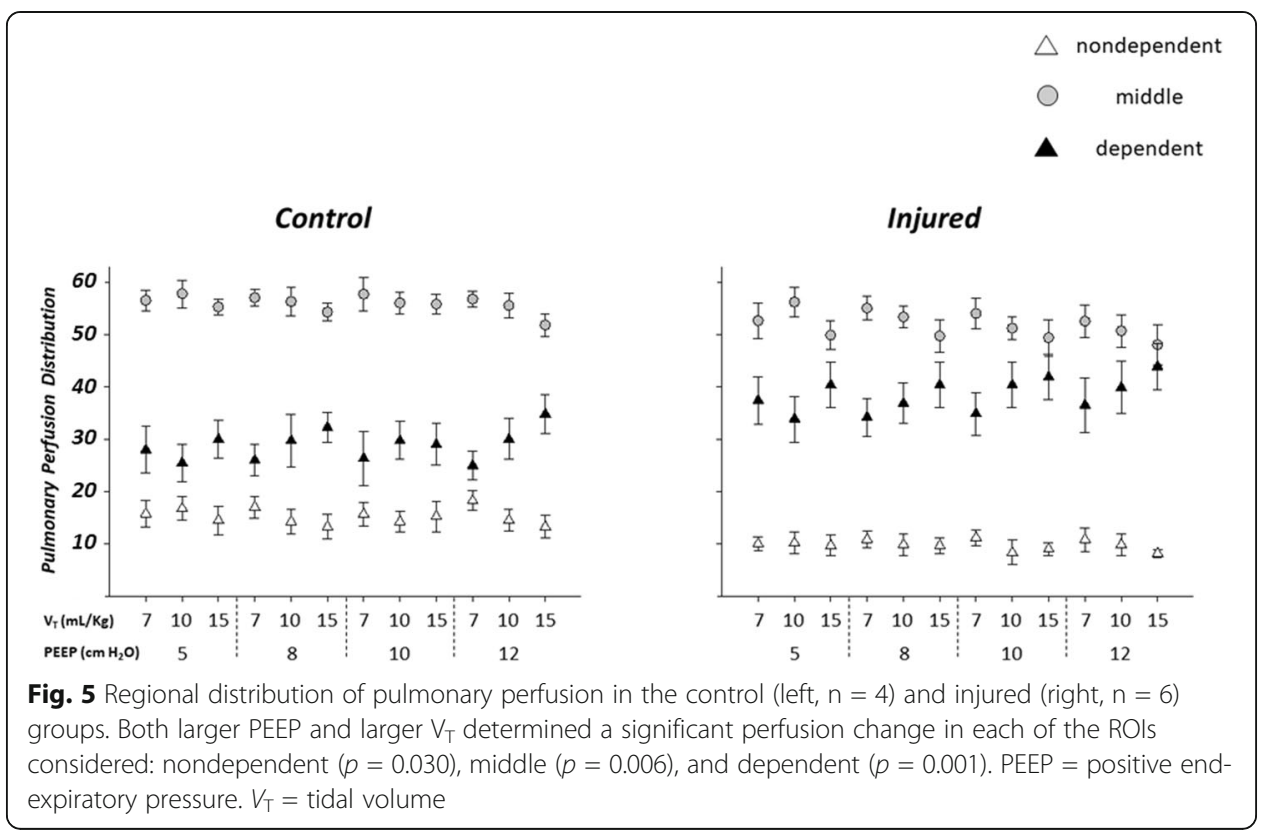

settings such as PEEP and $V_{\mathrm{T}}$, continuously, in real-time, and at the bedside. This information may be critical for a timely evaluation of the precision and efficacy of attempts to minimize some of the main ventilator-induced lung injury (VILI) mechanisms, particularly in the presence of alveolar collapse, common in the lungs of patients with the ARDS [19].

Our data highlight that airspaces collapse in the injured group altered the pulmonary regional ventilation response to different PEEP and $V_{\mathrm{T}}$ levels. Notwithstanding, when analyzing the effects of PEEP and $V_{\mathrm{T}}$ on regional perfusion, airspaces collapse did not seem to play a major role. Regarding regional perfusion, the mutual interaction between PEEP and tidal volume seemed to be more relevant. Our findings on regional ventilation may be interpreted as predominantly gravity-related, since the ventilation of the more dependent region exhibited a greater increase in its percentage with increasing $V_{\mathrm{T}}$ and PEEP in the injured group than in the control one. On the other hand, our findings on regional perfusion, where all regions were altered and the presence or not of lung injury did not have an effect, suggest that $V_{\mathrm{T}}$ and PEEP interacted all over the lung parenchyma on the redistribution of regional perfusion to the dependent zones [20, 21], also in agreement with pulmonary blood volume tidal redistribution [22].

Pulmonary perfusion can be affected by anesthesia and by mechanical ventilation, affecting arterial blood oxygenation [23-27]. The greatest determinant of pulmonary blood perfusion distribution is the difference between alveolar and pulmonary capillary pressures [28]. Perfusion increases down the gravitational gradient in the lung, due to hydrostatic forces and structural factors. Atelectasis is pronounced in the dependent lung regions, where perfusion of non-ventilated lung parenchyma produces a shunt effect of around 8-10\% of cardiac output in healthy lungs [24], and a greater shunt in injured lungs. In addition, nongravitational inhomogeneity of perfusion can reduce arterial blood oxygenation. Elevated airway pressures applied to the lung during mechanical ventilation can compromise venous return and redirect blood flow to dependent lung regions, with the effect being more marked at higher levels of PEEP and/or $V_{\mathrm{T}}$ [29]. Our data demonstrate that these effects can be regionally monitored, measured, and tracked in real-time and at the bedside by EIT. 
Our distributions of regional pulmonary perfusion at different PEEP and $V_{\mathrm{T}}$ levels may have been also partly influenced through hypoxic pulmonary vasoconstriction (HPV) [30]. In conditions of atelectasis, as in the injured group here, HPV could have been greater at low levels of PEEP and $V_{\mathrm{T}}$. Noteworthy, we have shown before that perfusion is similar, whether a region is collapsed is aerated but non-ventilated [13], findings that fit with observations by Benumof [31] - that HPV is the main mechanism of reduced blood flow in atelectatic regions, not mechanical obstruction.

The main limitation of our study may be in the animal model that is not capable of reproducing all of the key characteristics of lung injury in humans, for example in ARDS patients, where EIT titration of MV may be most helpful. Any animal model is relevant for only limited aspects of ARDS pathophysiology. However, if the specific characteristics of an animal model are carefully taken in account, and its findings are interpreted in the context of the study limitations, animal investigations can provide valid assessments of relevant elements of ARDS in human patients. The surfactant depletion by saline lavage model was developed based on the observation that ARDS is associated with depletion of surfactant from the air spaces and reduced concentrations of surfactant-associated proteins in bronchoalveolar lavage fluid [32]. However, determining precisely the extent to which the lung injury is caused by the saline lavage, by mechanical ventilation, or both remains challenging. Depletion of surfactant may be associated with lung injury via two mechanisms: greater lung collapse and increased likelihood of mechanical injury during repeated cycles of airspaces opening/closure, and impaired alveolar host defenses. Characteristically, saline lavage leads to almost immediate hypoxemia, which may be rapidly reversed by recruitment maneuvers, suggesting that the gas exchange abnormalities reflect collapsed alveoli with otherwise intact alveolar walls. The saline lavage by itself has little consequence in terms of permeability changes or inflammation [33], although TNF-alpha is detectable in lavage fluid. Despite surfactant depletion being an important feature of ARDS in humans, it usually appears as a consequence rather than the primary cause of lung injury [34]. In ARDS, surfactant abnormalities occur because of injury to the alveolar epithelium and exudation of protein-rich edema fluid into the alveolar spaces. Saline lavage of the lungs results in surfactant depletion in the absence of major alveolar epithelial damage. Epithelial damage occurs only when the saline lavage is followed by an injurious ventilatory strategy. Therefore, surfactant depletion followed by mechanical ventilation simulates established ARDS and provides information about the consequences of surfactant depletion, but it is less useful in modeling the initial pathophysiological mechanisms that lead to ARDS. The major advantage of the saline lavage model is that it provides an ideal way to test the effects of different ventilatory strategies on the development of lung injury [33].

The approach applied in this study for the determination of regional pulmonary perfusion by EIT presents some limitations. The regional time-impedance curves resulting from $10 \% \mathrm{NaCl}$ injection $[16,35,36]$ were fitted on a pixel-by-pixel basis by a gammavariate function to quantitatively assess regional perfusion $[17,18]$. The subtraction of the cardiac component of perfusion from mixed pixels while maintaining the net lung component by using an EIT gamma variate algorithm is an essential feature of this method. Such was made possible by the fitting also of the early cardiac component, also on a pixel-by-pixel basis by a corresponding gamma-variate function. However, at the 
edges of the heart, some challenging overlap between the behavior of lung and heart tissue may have remained, sometimes causing uncertainties in the double-function fitting process applied. Although the location of the cardiac chambers in humans could make this differentiation easier in the clinical setting, more studies on this subject are needed.

The maximal slope method applied is based on the assumption that no tracer leaves the ROI before the peak artery concentration is reached. Such assumption could be violated in the presence of the combination of high blood flow and low blood volume, leading to small estimation errors, provided that blood volume decreases by no more than one order of magnitude.

It is possible that some sodium chloride diffused outside the pulmonary blood vessels. In this situation, the solute that remains in the vessel will leave the lungs through the venous drainage while the diffused solute will tend to stay in the lungs, violating the conservation of mass principle (unless an extravascular compartment is accounted for). For the calculations of the maximal slope; however, the conservation of mass could still be applied correctly, since one of the assumptions is that there is no outflow of hypertonic saline before the peak of the pulmonary artery input function. In this case, the conservation of mass implies that all the solute that reaches the ROI (feeding vessel and extravascular compartment together), irrespective of whether it remains inside the vessels or not, came through the feeding artery.

EIT imaging has 2D and 3D features (the electrodes are placed within a single plane, but the finite mesh is 3D). Although reasonably large, the thickness of the EIT crosssectional slice $(\sim 15 \mathrm{~cm})$ may represent different proportions of the lungs, depending on the size and shape of the animal [4], without guarantee that most of the lung is represented in all animals, unless other imaging techniques are employed in parallel [37]. Finally, due to the low spatial resolution of EIT, the maximum slope time point might be slightly displaced (in time) among sub-regions within the ROI, likely causing inaccurate estimates of spatially averaged maximum slopes. The extent of this potential limitation deserves future studies.

\section{Conclusions}

Our findings suggest that ventilation of the most dependent lung region is greater with larger levels of PEEP and tidal volume in piglets with saline lavage-induced lung injury. Moreover, pulmonary blood flow of all lung regions is affected by larger levels of PEEP and tidal volume, both in control animals and in piglets with saline lavage-induced lung injury. They also suggest that EIT is a promising bedside and noninvasive clinical tool for continuous and real-time monitoring of pulmonary ventilation that can be especially useful in severe mechanically ventilated patients such as those with ARDS. EIT can help to optimize mechanical ventilation settings, detect complications such as derecruitment, and provide estimates of perfusion distribution. More clinical validation studies are awaited to explore the full potential of the technology.

\section{Abbreviations}

ANOVA: Analysis of variance; ARDS: Acute respiratory distress syndrome; EIT: Electrical impedance tomography; $\mathrm{F}_{1} \mathrm{O}_{2}$ : Fraction of inspired oxygen; HPV: Hypoxic pulmonary vasoconstriction; I:E: Inspiratory-to-expiratory ratio; MV: Mechanical ventilation; $\mathrm{PaO}_{2} / \mathrm{F}_{1} \mathrm{O}_{2}$ : Arterial partial pressure of $\mathrm{O}_{2}$ and fraction of inspired oxygen ratio; PEEP: Positive end-expiratory pressure; ROIs: Regions-of-interest; RR: Respiratory rate; VILI: Ventilator-induced lung injury; $V_{T}$ : Tidal volume 


\section{Acknowledgements}

The authors would like to acknowledge Prof. Andrew Farmery and Dr Luigi Camporota for helpful discussions and Agneta Roneus, Kerstin Ahlgren, Mariette Anderson, Liselotte Pihl, Maria Swälas, and Monica Segelsjö for their expertise and technical assistance.

\section{Authors' contributions}

JBB contributed to the data acquisition, analysis, and interpretation of data, and prepared first draft of the manuscript. JNC contributed to the conception and design of the work, data acquisition, and manuscript revision. DCC contributed to the data acquisition and manuscript revision. GH and AL contributed to the conception and design of the work, and helped in the manuscript revision. FF contributed to the conception and design of the work, data acquisition, analysis, and interpretation and manuscript revision. All authors read and approved the final manuscript.

\section{Funding}

Anders Larsson and Göran Hedenstierna were supported by the Swedish Lung and Heart Foundation (20170531) and the Swedish Research Council (K2015-99X-2273101-4), and Federico Formenti was supported by the Medical Research Council (MC_PC_17164) and The Physiological Society (Formenti 2018).

\section{Availability of data and materials}

The datasets used and/or analyzed during the current study are available from the corresponding author on reasonable request.

\section{Ethics approval and consent to participate}

The study was performed at the Hedenstierna Laboratory, Uppsala University. The Regional Animal Ethics Committee approved the study.

\section{Consent for publication}

Not applicable.

\section{Competing interests}

The authors declare that they have no competing interests.

\section{Author details}

${ }^{1}$ Centre for Human and Applied Physiological Sciences, King's College London, London, UK. ${ }^{2}$ Nuffield Division of Anaesthetics, University of Oxford, Oxford, UK. ${ }^{3}$ Hedenstierna Laboratory, Department of Medical Sciences, Uppsala University, Uppsala, Sweden. ${ }^{4}$ Hedenstierna Laboratory, Department of Surgical Sciences, Uppsala University, Uppsala, Sweden.

Received: 20 October 2019 Accepted: 30 January 2020

Published online: 21 February 2020

\section{References}

1. Retamal J, Hurtado D, Villarroel N, Bruhn A, Bugedo G, Amato MBP, Costa ELV, Hedenstierna G, Larsson A, Borges JB (2018) Does regional lung strain correlate with regional inflammation in acute respiratory distress syndrome during nonprotective ventilation? An Experimental Porcine Study. Crit Care Med 46:e591-e599

2. Gattinoni L, Pelosi P, Crotti S, Valenza F (1995) Effects of positive end-expiratory pressure on regional distribution of tidal volume and recruitment in adult respiratory distress syndrome. Am J Respir Crit Care Med 151:1807-1814

3. Frerichs I, Amato MB, van Kaam AH, Tingay DG, Zhao Z, Grychtol B, Bodenstein M, Gagnon H, Bohm SH, Teschner E, Stenqvist O, Mauri T, Torsani V, Camporota L, Schibler A, Wolf GK, Gommers D, Leonhardt S, Adler A, group Ts (2017) Chest electrical impedance tomography examination, data analysis, terminology, clinical use and recommendations: consensus statement of the TRanslational EIT developmeNt stuDy group. Thorax 72:83-93

4. Costa EL, Lima RG, Amato MB (2009) Electrical impedance tomography. Curr Opin Crit Care 15:18-24

5. Blankman P, Hasan D, van Mourik MS, Gommers D (2013) Ventilation distribution measured with ElT at varying levels of pressure support and Neurally Adjusted Ventilatory Assist in patients with ALI. Intensive Care Med 39:1057-1062

6. Morais CCA, Koyama Y, Yoshida T, Plens GM, Gomes S, Lima CAS, Ramos OPS, Pereira SM, Kawaguchi N, Yamamoto H, Uchiyama A, Borges JB, Vidal Melo MF, Tucci MR, Amato MBP, Kavanagh BP, Costa ELV, Fujino Y (2018) High positive end-expiratory pressure renders spontaneous effort noninjurious. Am J Respir Crit Care Med 197:1285-1296

7. Yoshida T, Fujino Y, Amato MB, Kavanagh BP (2017) Fifty years of research in ARDS. Spontaneous Breathing during Mechanical Ventilation. Risks, Mechanisms, and Management. Am J Respir Crit Care Med 195:985-992

8. Yoshida T, Nakahashi S, Nakamura MAM, Koyama Y, Roldan R, Torsani V, De Santis RR, Gomes S, Uchiyama A, Amato MBP, Kavanagh BP, Fujino Y (2017) Volume-controlled ventilation does not prevent injurious inflation during spontaneous effort. Am J Respir Crit Care Med 196:590-601

9. Yoshida T, Torsani V, Gomes S, De Santis RR, Beraldo MA, Costa EL, Tucci MR, Zin WA, Kavanagh BP, Amato MB (2013) Spontaneous effort causes occult pendelluft during mechanical ventilation. Am J Respir Crit Care Med 188:1420-1427

10. Yoshida T, Uchiyama A, Matsuura N, Mashimo T, Fujino Y (2012) Spontaneous breathing during lung-protective ventilation in an experimental acute lung injury model: high transpulmonary pressure associated with strong spontaneous breathing effort may worsen lung injury. Crit Care Med 40:1578-1585

11. Bachmann MC, Morais C, Bugedo G, Bruhn A, Morales A, Borges JB, Costa E, Retamal J (2018) Electrical impedance tomography in acute respiratory distress syndrome. Crit Care 22:263

12. Frerichs I, Hahn G, Golisch W, Kurpitz M, Burchardi H, Hellige G (1998) Monitoring perioperative changes in distribution of pulmonary ventilation by functional electrical impedance tomography. Acta Anaesthesiol Scand 42:721-726 
13. Borges JB, Suarez-Sipmann F, Bohm SH, Tusman G, Melo A, Maripuu E, Sandstrom M, Park M, Costa EL, Hedenstierna G Amato M, (2012) Regional lung perfusion estimated by electrical impedance tomography in a piglet model of lung collapse. J Appl Physiol 112:225-236

14. Costa EL, Borges JB, Melo A, Suarez-Sipmann F, Toufen C Jr, Bohm SH, Amato MB (2009) Bedside estimation of recruitable alveolar collapse and hyperdistension by electrical impedance tomography. Intensive Care Med 35:1132-1137

15. Victorino JA, Borges JB, Okamoto VN, Matos GF, Tucci MR, Caramez MP, Tanaka H, Sipmann FS, Santos DC, Barbas CS, Carvalho CR, Amato MB (2004) Imbalances in regional lung ventilation: a validation study on electrical impedance tomography. Am J Respir Crit Care Med 169:791-800

16. Frerichs I, Hinz J, Herrmann P, Weisser G, Hahn G, Quintel M, Hellige G (2002) Regional lung perfusion as determined by electrical impedance tomography in comparison with electron beam CT imaging. IEEE Trans Med Imaging 21:646-652

17. Meier P, Zierler KL (1954) On the theory of the indicator-dilution method for measurement of blood flow and volume. $J$ Appl Physiol 6:731-744

18. Thompson HK Jr, Starmer CF, Whalen RE, McIntosh HD (1964) Indicator Transit Time Considered as a Gamma Variate. Circ Res 14:502-515

19. Borges JB, Okamoto VN, Matos GF, Caramez MP, Arantes PR, Barros F, Souza CE, Victorino JA, Kacmarek RM, Barbas CS, Carvalho CR, Amato MB (2006) Reversibility of lung collapse and hypoxemia in early acute respiratory distress syndrome. Am J Respir Crit Care Med 174:268-278

20. Glenny R, Robertson HT (2011) Distribution of perfusion. Compreh Physiol 1:245-262

21. Glenny RW, Polissar L, Robertson HT (1991) Relative contribution of gravity to pulmonary perfusion heterogeneity. J Appl Physiol (1985) 71:2449-2452

22. Cronin JN, Crockett DC, Farmery AD, Hedenstierna G, Larsson A, Camporota L, Formenti F (2020 Mechanical ventilation redistributes blood to poorly ventilated areas in experimental lung injury. Crit Care Med 48:e200-e208

23. Musch G, Bellani G, Vidal Melo MF, Harris RS, Winkler T, Schroeder T, Venegas JG (2008) Relation between shunt, aeration, and perfusion in experimental acute lung injury. Am J Respir Crit Care Med 177:292-300

24. Hedenstierna G (2005) Pulmonary perfusion during anesthesia and mechanical ventilation. Minerva Anestesiol 71:319-324

25. Formenti F, Bommakanti N, Chen R, Cronin JN, McPeak H, Holopherne-Doran D, Hedenstierna G, Hahn CEW, Larsson A Farmery AD (2017) Respiratory oscillations in alveolar oxygen tension measured in arterial blood. Sci Rep 7:7499

26. Formenti F, Chen R, McPeak H, Murison PJ, Matejovic M, Hahn CE, Farmery AD (2015) Intra-breath arterial oxygen oscillations detected by a fast oxygen sensor in an animal model of acute respiratory distress syndrome. Br J Anaesth 114:683-688

27. Crockett DC, Cronin JN, Bommakanti N, Chen R, Hahn CEW, Hedenstierna G, Larsson A, Farmery AD, Formenti F (2019) Tidal changes in $\mathrm{PaO} 2$ and their relationship to cyclical lung recruitment/derecruitment in a porcine lung injury model. $\mathrm{Br} J$ Anaesth 122:277-285

28. Permutt S, Howell JB, Proctor DF, Riley RL (1961) Effect of lung inflation on static pressure-volume characteristics of pulmonary vessels. J Appl Physiol 16:64-70

29. Hedenstierna G, White FC, Mazzone R, Wagner PD (1979) Redistribution of pulmonary blood flow in the dog with PEEP ventilation. J Appl Physiol Respir Environ Exerc Physiol 46:278-287

30. Moudgil R, Michelakis ED, Archer SL (2005) Hypoxic pulmonary vasoconstriction. J Appl Physiol (1985) 98:390-403

31. Benumof JL (1979) Mechanism of decreased blood flow to atelectatic lung. J Appl Physiol Respir Environ Exerc Physiol 46:1047-1048

32. Lachmann B, Robertson B, Vogel J (1980) In vivo lung lavage as an experimental model of the respiratory distress syndrome. Acta Anaesthesiol Scand 24:231-236

33. Matute-Bello G, Frevert CW, Martin TR (2008) Animal models of acute lung injury. Am J Physiol Lung Cell Mol Physiol 295:L379-L399

34. Petty TL, Reiss OK, Paul GW, Silvers GW, Elkins ND (1977) Characteristics of pulmonary surfactant in adult respiratory distress syndrome associated with trauma and shock. Am Rev Respir Dis 115:531-536

35. Brown BH, Leathard A, Sinton A, McArdle FJ, Smith RW, Barber DC (1992) Blood flow imaging using electrical impedance tomography. Clin Phys Physiol Meas 13(Suppl A):175-179

36. Trautman ED, Newbower RS (1983) A practical analysis of the electrical conductivity of blood. IEEE Trans Biomed Eng 30: $141-154$

37. Cronin JN, Borges JB, Crockett DC, Farmery AD, Hedenstierna G, Larsson A, Tran MC, Camporota L, Formenti F (2019) Dynamic single-slice CT estimates whole-lung dual-energy $C T$ variables in pigs with and without experimental lung injury. Intensive Care Med Exp 7:59

\section{Publisher's Note}

Springer Nature remains neutral with regard to jurisdictional claims in published maps and institutional affiliations. 